\title{
Queimadura nasal por ácido nítrico
}

Nasal burn by nitric acid Fernando P. Gaspar-Sobrinbo ${ }^{1}$, Francisco $S$.
Nascimento Sampaio ${ }^{2}$, Hélio A. Lessa
Palavras-chave: nariz, queimadura, urgência, ácido nítrico. Keywords: nitric acid, nose, urgency, burn.

\section{INTRODUÇÃO}

Substâncias capazes de causar queimadura química em pele e mucosas são acondicionadas inadvertidamente em recipientes de bebidas e medicamentos ou em embalagens de aspecto inofensivo.

\section{APRESENTAÇÃO DO CASO}

Uma mulher com 33 anos instilou no nariz produto à base de ácido nítrico, conhecido como "água forte" e usado profissionalmente pelo cônjuge. O frasco com ácido foi confundido com

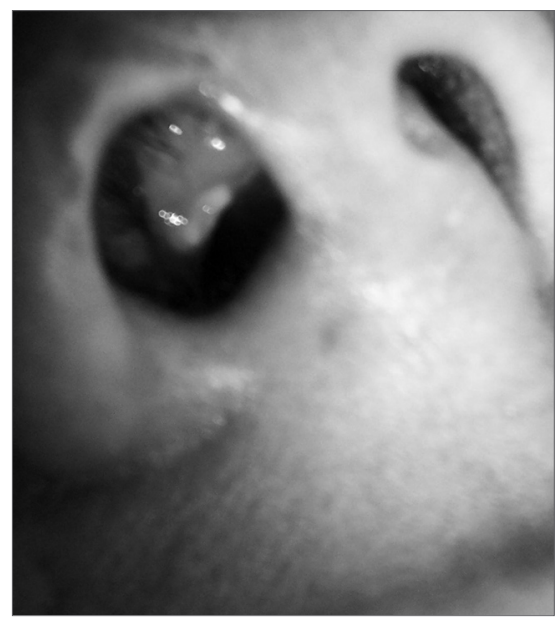

Figura 1. Asa do nariz e vestíbulo com queimadura de aspecto amarelo-acinzentado circundada por eritema. o recipiente de um descongestionante tópico nasal. Queixava-se de dor intensa, ardor, obstrução nasal e lacrimejamento. Rinoscopia evidenciou queimadura na asa do nariz e vestíbulo nasal, de aspecto amarelado, circundada por eritema (Figura 1). Com a cabeça flexionada, foi realizada lavagem por 15 minutos. Foi orientada a lavar diariamente o local afetado, evitar exposição à luz solar e usar analgésico. Revisões até o sexto mês não revelaram seqüela.

\section{DISCUSSÃO}

Os autores não encontraram na literatura relato de acidente com ácido nítrico por instilação no nariz. O ácido nítrico é líquido à temperatura ambiente, sendo que seu aspecto varia de incolor a amarelo ou marrom avermelhado, e apresenta odor forte ${ }^{1}$. O ácido nítrico é usado na fabricação de pesticidas, fertilizantes, explosivos, na indústria farmacêutica, e para limpar e dar brilho a metais.

Como não existe tratamento específico para queimadura por ácido nítrico, a terapia preconizada é de suporte. O serviço de toxicologia deve ser consultado. Corticóide é usado empiricamente em sintomas pulmonares ${ }^{1}$. Não sabemos se corticóide tópico nasal ou sistêmico pode trazer algum benefício em lesões nasais.
É possível que indivíduos com rinite crônica estejam particularmente sujeitos a acidentes como este. O esclarecimento da população e a conscientização dos profissionais de saúde são aspectos importantes na prevenção de intoxicações em pacientes com rinite ${ }^{2}$.

\section{COMENTÁRIOS FINAIS}

Substâncias nocivas à saúde são mantidas próximas ao homem, sem proteção ou advertência, e não raro envolve acidentes com a orelha, nariz, e garganta. Deste modo, o otorrinolaringologista poderá ser solicitado a avaliar e tratar esses acidentes, além de trabalhar ativamente com a prevenção junto à comunidade.

\section{REFERÊNCIAS BIBLIOGRÁFICAS}

1.Nitric acid: information and recommendations for doctors at hospital/emergency departments. In: BASF Chemical Emergency Medical Guidelines. Disponível em: http://www.corporate.basf.com/ en/sustainability/gesellschaft/gesundheit/arbeitsmedizin/leitlinien/beispiel. htm?id=JUYTI5oRJbcp3-Y. Acesso em: 8 de fevereiro de 2004

2.Balbani APS, Duarte JG, Sanchez TG, Mello Jr JF, Butugan O. Perfil das intoxicações por medicamentos utilizados no tratamento das rinites na cidade de São Paulo. Rev Bras Otorrinolaringol 1998;64:33-40.

' Mestre em Medicina e Saúde, Professor Substituto do Departamento de Cirurgia da Faculdade de Medicina da Universidade Federal da Bahia. Especialista em Otorrinolaringologia, Professor Substituto do Departamento de Cirurgia da Faculdade de Medicina da Universidade Federal da Bahia ${ }^{3}$ Doutor em Cirurgia, Professor Adjunto do Departamento de Cirurgia da Faculdade de Medicina da Universidade Federal da Bahia. Serviço de Otorrinolaringologia do Hospital Universitário Prof. Edgard Santos da Faculdade de Medicina da Bahia da Universidade Federal da Bahia. Endereço para correspondência: Fernando P. G. Sobrinho - Av. Augusto Viana 40110-160 Salvador BA. E-mail: fpgsobrinho@ig.com.br Este artigo foi submetido no SGP (Sistema de Gestão de Publicações) da RBORL em 26 de abril de 2005. Cod. 270. Artigo aceito em 1 de janeiro de 2007 